\title{
A green, microwave-mediated, multicomponent synthesis of pyrimidine and pyrimidinone derivatives
}

\author{
Augusto L. Xavier, ${ }^{a}$ Daniel S. Alexandrino, ${ }^{b}$ Emerson P. S. Falcão, ${ }^{b}$ Rajendra M. \\ Srivastava ${ }^{\mathrm{a}}$ and Janaina V. dos Anjos ${ }^{\mathrm{a}, \star}$
}

${ }^{a}$ Departamento de Química Fundamental, Universidade Federal de Pernambuco, Cidade Universitária, 50740-540, Recife, PE, Brazil ; ${ }^{b}$ Centro Acadêmico de Vitória, Universidade Federal de Pernambuco, Bela Vista, 55608-680, Vitória de Santo Antão, PE, Brazil.

*Corresponding author: janaina.anjos@ufpe.br

Keywords: microwave irradiation, pyrimidine, pyrimidinone.

\section{INTRODUCTION}

Pyrimidine and their oxo-derivatives are well-known for their biological properties and high potential in drug discovery ${ }^{1}$. Thus, our group has been involved in synthesizing and testing the pharmacological activities of these classes of heterocycles. ${ }^{2}$ Several methodologies are available for synthesizing those rings. ${ }^{1}$ In most cases, it is first prepared a Michael intermediate from an aldehyde and a "methylene active" compound and then this adduct can react with amidines, guanidines, urea, thiourea, methylisourea or methylisothiourea, in the presence of organic bases as catalysts. $^{3}$ This process may take two days of lab work for the obtention of a sole product. In this work, we describe a rapid, green, microwave mediated and multicomponent synthesis of pyrimidines and pyrimidinones using water as solvent.

\section{RESULTS AND DISCUSSION}

Microwave irradiation has been used in organic reactions in order to enhance chemical yields or even reduce reaction times. In our synthetic approach, the aromatic aldehydes (1a-j) were allowed to react with ethyl cyanoacetate (2) or malononitrile (3) and benzamidine hydrochloride (3), in the presence of potassium carbonate $(2.0 \mathrm{eq})$ in water, under microwave irradiation to afford the pyrimidinones $\mathbf{4 a - j}$ or the pyrimidines 6a-j in moderate yields (Figure).<smiles>[M]C=O</smiles><smiles>CCOC(=O)CC#N</smiles><smiles>N=C(N)c1ccccc1</smiles>

1a-j 2 (1.3 eq)

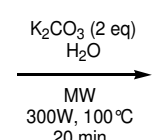
$20 \mathrm{~min}$
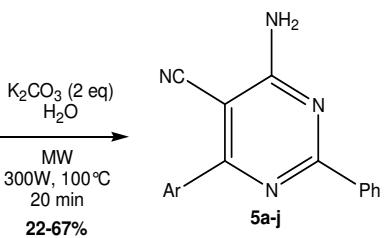

1a-j

Figure.

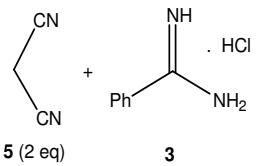

$22-67 \%$

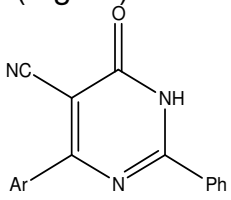

4a-j

The reaction was also performed without microwave irradiation, using the same solvent (water) and stoichiometric quantities for the reagents and benzaldehyde, in reflux. For 6-oxo-2,4-diphenyl-1,6dihydro-pyrimidine-5-carbonitrile, the yield was $18 \% 8$ hours after the beginning of the reaction. The pyrimidine derivative was not detectable in TLC after the same reaction time.

Table. Pyrimidinones and pyrimidines synthesized

\begin{tabular}{ccc|ccc}
\hline Comp. & $\mathbf{A r}$ & Yield & Comp. & Ar & Yield \\
\hline $\mathbf{4 a}$ & $\mathrm{Ph}$ & $36 \%$ & $\mathbf{6 a}$ & $\mathrm{Ph}$ & $56 \%$ \\
$\mathbf{4 b}$ & $m$-Tolyl & $47 \%$ & $\mathbf{6 b}$ & $m$-Tolyl & $36 \%$ \\
$\mathbf{4 c}$ & $p-\mathrm{Tolyl}$ & $26 \%$ & $\mathbf{6 c}$ & $p$-Tolyl & $47 \%$ \\
$\mathbf{4 d}$ & $p-\mathrm{ClPh}$ & $36 \%$ & $\mathbf{6 d}$ & $p-\mathrm{ClPh}$ & $70 \%$ \\
$\mathbf{4 e}$ & $p-\mathrm{BrPh}$ & $46 \%$ & $\mathbf{6 e}$ & $p-\mathrm{BrPh}$ & $48 \%$ \\
$\mathbf{4 f}$ & $p-\mathrm{FPh}$ & $32 \%$ & $\mathbf{6 f}$ & $p-\mathrm{FPh}$ & $27 \%$ \\
$\mathbf{4 g}$ & $p-\mathrm{OCH}_{3} \mathrm{Ph}$ & $41 \%$ & $\mathbf{6 g}$ & $p-\mathrm{OCH}_{3} \mathrm{Ph}$ & $48 \%$ \\
$\mathbf{4 h}$ & $m-\mathrm{NO}_{2} \mathrm{Ph}$ & $20 \%$ & $\mathbf{6 h}$ & $m-\mathrm{NO}_{2} \mathrm{Ph}$ & $40 \%$ \\
$\mathbf{4 i}$ & $p-\mathrm{NO}_{2} \mathrm{Ph}$ & $43 \%$ & $\mathbf{6 i}$ & $p-\mathrm{NO}_{2} \mathrm{Ph}$ & $67 \%$ \\
$\mathbf{4 j}$ & $3,4-\mathrm{diClPh}^{\mathbf{j}}$ & $51 \%$ & $\mathbf{6 j}$ & $3,4-\mathrm{diClPh}^{2}$ & $22 \%$ \\
\hline
\end{tabular}

In a typical procedure, the aldehyde, the methylene active reagent, benzamidine hydrochloride and potassium carbonate were mixed in a microwave vial with $10 \mathrm{~mL}$ of water. The vial was placed in a CEM microwave reactor to react using $300 \mathrm{~W}$ of potency, at $100^{\circ} \mathrm{C}$, for 20 minutes. The reaction was then allowed to cool to room temperature and the precipitate was filtered and washed several times with water. The crude compound was recrystallized from ethanol to afford the pure pyrimidine or pyrimidinone derivative.

\section{CONCLUSION}

We have accomplished the multicomponent synthesis of twenty pyrimidine and pyrimidinone derivatives using cheap and non-poluent reagents such water and potassium carbonate, under microwave irradiation. This procedure proved to be cleaner and faster than the usual methodology.

\section{ACKNOWLEDGEMENTS}

CNPq, PRONEX-FACEPE.

\section{REFERENCES}

${ }^{1}$ Brown, D.J.; Mason, S.F. The Pyrimidines, Interscience Publishers, New York, 1962, pp 31-115.

${ }^{2}$ Mendonça Jr, F.J.B.; dos Anjos, J.V.; Falcão, E.P.S.; Melo, S.J.; Srivastava, R.M. Heterocycl. Commun. 2005, 11, 479.

${ }^{3}$ Falcão, E.P.S.; Melo, S.J.; Srivastava, R.M.; Catanho, M.T.J.A.; Nascimento, S.C. Eur. J. Med. Chem. 2006, 41276.

$14^{\text {th }}$ Brazilian Meeting on Organic Synthesis - $14^{\text {th }}$ BMOS - September 01-05, 2011-Brasilia, Brazil 